\title{
CORRECTION
}

The news story SAAD Dental Nurse's prize, page 10 in the spring issue of Vital, implied that the adjacent photograph featured the winner, Sharon Williams, at SAAD's annual conference. This photograph did not in fact depict Sharon but another award winner. Apologies to those concerned. The real Sharon is pictured here!

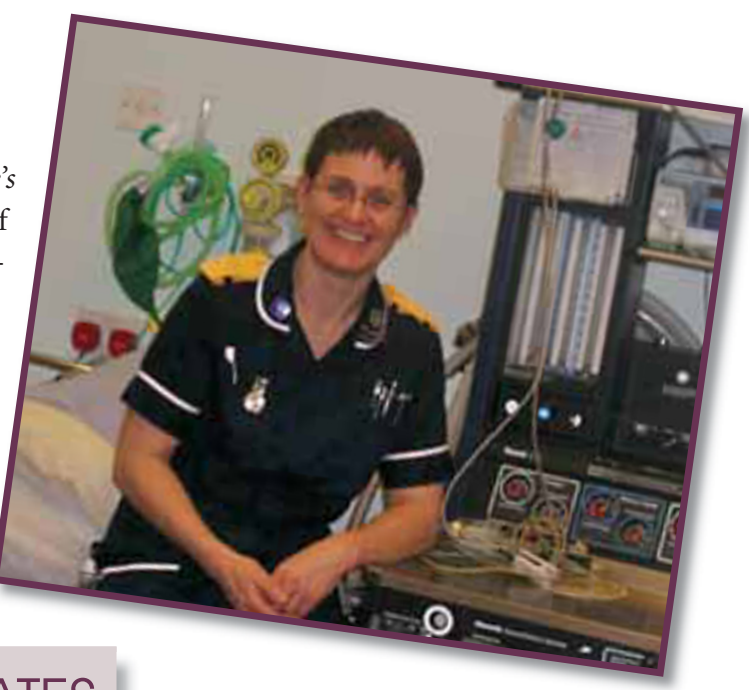

\section{PAMELA CELEBRATES 50 YEARS AS A DENTAL NURSE}

Miss Pamela Waugh, a dental nurse in Lewes, East Sussex, will be celebrating 50 years of dental nursing this September.

Pamela started nursing when she left school and has worked continuously since then. In the late 1960s she spent a few years working in Canada but has otherwise dedicated herself to nursing in the South East of England.

'Pamela has worked at our practice for 38 years, said dentist Gary Burgess of North Street Dental Practice, Lewes. 'She is a truly loyal employee, organising the nursing examinations at our practice for many years. She has given a huge part of her life to the profession.' The team at North Street are planning a special celebration for Pamela.

DID YOU KNOW? Vital was launched in 2003 as a team supplement to the British Dental Journal. The summer 2008 issue will be sent to over 20,000 DCPs.

\section{WIN A PRIZE FOR YOUR PROJECT}

DCPs at any stage of their career, in training, postgraduate or practising, are invited to enter for this year's Premier Awards which are offering a total of $\mathfrak{E} 6,000$ in prizes.

The deadline is 1 September and prizes will be presented at King's College London on 29 November. Categories in the competition are: infection control; health and safety; consent; record keeping; or team working and skill mix. For application forms contact Sarah Cunliffe at Dental Protection at sarah.cunliffe@mps.org.uk.

\section{HOTS \\ Name: Sarah Godley \\ Age: 41 \\ Town: Sheffield \\ Loves: Food! \\ Hates: Dog dirt \\ Hobbies: Swimming and reading \\ Job: Oral Health Promotion \\ (Special Needs)}

How did you get your job? I've worked for the CDS for 10 years. I did my oral health exam three years ago. When this job came up I jumped at the chance.

How did you end up working in dentistry? I saw an article in Jackie magazine about dental nursing and thought 'I could do that!
What do you

enjoy most

about your job?

The variety: one day I might be doing an event at a fire station, the next day I might be in a school or clinic talking to people on a one-to-one basis.

What is the most challenging part of your job? Getting someone who never brushes their teeth to take an interest.

Would you recommend a career in dentistry? Yes, there is so much variety, you can do CDS, general practice (private or NHS), hospital work or oral health promotion.

What three things could you not live without? A cup of tea, hand cream, and a toothbrush, of course! 